\title{
The Influence of Parents' Backgrounds, Beliefs about English Learning, and a Dialogic Reading Program on Thai Kindergarteners' English Lexical Development
}

\author{
Anongnad Petchprasert ${ }^{1}$ \\ ${ }^{1}$ School of Liberal Arts, University of Phayao, Phayao, Thailand \\ Correspondence: Anongnad Petchprasert, School of Liberal Arts, University of Phayao, Phayao, Thailand.
}

Tel: 66-54-466-660. E-mail: anongnad.pe@up.ac.th

\author{
Received: November 13, 2013 Accepted: December 23, $2013 \quad$ Online Published: February 12, 2014 \\ doi:10.5539/elt.v7n3p50 URL: http://dx.doi.org/10.5539/elt.v7n3p50
}

The research is financed by School of Liberal Arts, University of Phayao, Thailand.

\begin{abstract}
This study investigated parents' backgrounds and their beliefs about English language learning, and compared the receptive English vocabulary development of three to six year-old-Thai children before and after participating in a parent-child reading program with the dialogic reading (DR) method. Fifty-four single parents of 54 children voluntarily participated in the study. The parents were surveyed to determine if their demographic data, beliefs, and DR method affected their children's vocabulary development. The children were tested on fourteen English words before and after participating in the program. The results showed that parents' beliefs about English language learning affected expectations on their children's language success. In addition, the children's achievement was related to the use of DR method. The children yielded significant greater gains in knowledge of vocabulary and their ability to infer the meanings from pictures after engaging in the reading program.
\end{abstract}

Keywords: early literacy, parent-child reading, attitudes, family, vocabulary

\section{Introduction}

The literature on early literacy has shown that parents' characteristics and parental involvement in children's reading are important in predicting their academic achievement (Davis-Keen, 2005; Lee \& Bowen, 2006). Several researchers and educators investigated the mechanisms for understanding the influence of parents' characteristics and a reading intervention on children's early literacy (Gardner, 1985; Hart \& Risley, 1995; Storch \& Whitehurst, 2001; Lee \& Bowen, 2006). However, there has been less work on how factors such as parents' income, education, frequency of reading, and beliefs are associated with Thai children's vocabulary achievement. Thus, the researcher proposed a theoretically based study to elucidate the influence of the factors like parent-child characteristics, parent's beliefs, and a dialogic reading method on Thai kindergarteners' lexical development.

\subsection{Parent Backgrounds and Frequency of Reading with a Child}

Parents with variation of backgrounds contribute to different types of children educational involvement because they are not the same in terms of types of behaviors, attitudes, perceptions, socioeconomic status (SES), and educational attainment (Lee \& Bowen, 2006). Parents with low levels of education may be less involved at their children's school activities due to several factors including a lack of knowledge of the school system, or their own negative educational experiences (Lee \& Bowen, 2006). One provocative finding in the Snow, Burns, and Griffin's (1998) study was that children from low-income families tended to have limited exposure to books, and underdeveloped literacy and language skills. In addition, Hart and Risley (1995) found that the amount that parents talked to their children was associated with the parents' socioeconomic status. High-income parents tended to be taciturn and professionals were talkative, while working-class parents varied greatly from the most talkative to the most taciturn.

The frequency of parent-child reading is one important issue that many educators shed light on since it is 
associated with children's vocabulary and conceptual knowledge (Storch \& Whitehurst, 2001). Drawing on Neuman's (1999) work, children would gain in emergent literacy including alphabet knowledge and print concept when they increasingly accessed storybook reading. In Thailand, approximately $40 \%$ of Thai families reported that they never read to their children. Even more concerning is that parents reported that their children also never read a book by themselves (National Statistical Office, 2011).

\subsection{Self-Evaluation of English Competence}

With respect to Short's (1993) work, self-evaluation allows participants to evaluate a specific piece of their own work or judge their learning progress; it offers participants opportunities for reflection, as well as encourages the participants to take responsibility for assessment. A number of empirical studies indicated an increase in productivity and autonomy, motivation, and retention rates among participants when self-evaluation was utilized. Also, it was found that self-evaluation reduced frustration among the respondents (Saito, 2003; Chappuis \& Stiggins, 2002; Short, 1993). Several researchers and educators have developed self-assessments to measure English language ability. One of those instruments is the self-evaluation of English competence developed by Professor Richard Clémont and his colleague (Clémont \& Baker, 2001). The self-evaluation consists of four 6-point scales. In utilizing this evaluation, participants will indicate how well they can use English in terms of reading, writing, speaking, and comprehension. To explore the parents' English competence in the present study, the researcher used the self-evaluation of English competence (Clémont \& Baker, 2001) in an analysis of the parents' perceptions of their English ability.

\subsection{Beliefs about Language Learning}

According to Gardner (1985), one of factors in second language (L2) development for young children is parents' beliefs or attitudes toward language learning. Sung and Padilla's (1998) work showed that the parents demonstrated positive attitudes toward their children's foreign language (FL) learning. As a result, parents' beliefs about language learning were important factors contributing to children's L2 development. Since information concerning beliefs about L2 learning among parents whose young children were studying English as a foreign language (EFL) was also a central part of this study, the Beliefs about Language Learning Inventory version 2.0 (BALLI) was employed. BALLI has been used in several studies with different language translations. For example, Wang (1996) found that the participants had different beliefs and used a variety of language learning strategies. BALLI was distributed to the participants to investigate beliefs about language learning. The findings showed that a majority of the unsuccessful language learners tended to have negative beliefs about English learning. Vibulphol (2004) investigated beliefs about language learning of pre-service teachers who studied English as a foreign language (EFL) in Thailand. The participants were 42 pre-service EFL teachers at two universities in Thailand. The findings showed that a majority of the participants possessed the ability to learn English. Concerning the nature of English learning, many of them believed that it was best to learn English in an English-speaking country. They also believed that it was important to learn grammar rules, vocabulary, and culture in English classes. All pre-service teachers realized that vocabulary was important in learning a second language. Interestingly, their instruction appeared to be affected by their beliefs since all of them reported that they always included vocabulary instruction as a part of their lesson plans.

\subsection{Dialogic Reading}

As initiated by Whitehurst and colleagues (1988), dialogic reading (DR) is a form of shared reading that encourages interactions between parents and their children. As defined, DR changes a role of shared bookreading so that a parent helps a child become a teller of the story. The parent becomes the listener, the questioner, and the audience for the child (Whitehurst, n. d.). Some of the benefits of DR include increasing children's alphabetic and non-alphabetic languages (Chow \& McBride-Chang, 2003; Whitehurst et al., 1994), receptive vocabulary (Raikes, Alexander, Luze, Tamis-LeMonda, Brooks-Gunn, Constantine, Banks, Abigail, \& Rodriguez, 2006; Chow, McBride-Chang, Cheung, \& Chow, 2008), sound and letter identification, emergent writing skills, knowledge of print concepts (Bus, van IJzendoorn, \& Pellegrini, 1995), and interest in reading (Chow, McBride-Chang, Cheung, \& Chow, 2008).

Following the fundamental reading strategies in dialogic reading, the PEER sequence is used in the present study. The sequence is described as follows. An adult:

1) Prompts a child to say something about the book;

2) Evaluates the child's response;

3) Expands the child's response by rephrasing and adding information to it; and

4) Repeats the prompt to make sure the child has learned from the expansion. 
Several empirical studies had been conducted to investigate the benefits and the effectiveness of DR for children from different backgrounds such as socioeconomic status and native languages. For example, Sim (2012) investigated the influence of two forms of a shared reading intervention: dialogic reading and dialogic reading with the additional of print referencing. Eighty parents and their four to six year-old-children participated in the study. Pretest and posttest were used to measure the children's language skills. Oral language, phonological awareness skill, alphabet knowledge, and concepts about print were assessed. Results showed that the children's vocabulary, rhyme, and concept about print referencing were significantly improved. Opel, Ameer, and Aboud (2009) examined the effectiveness of a four-week dialogic reading intervention with rural Bangladeshi preschoolers with the intention of increasing their expressive vocabulary. Eighty preschoolers were randomly selected from five preschools. Their vocabulary, measured in terms of definitions, was tested on 170 words before and after the program and compared with that of control children who participated in a regular language program. Both groups read storybooks with illustrations. The mean scores of the dialogic reading program children significantly increased from $26 \%$ to $54 \%$ whereas the control children remained at the same level. Chow and McBride-Chang (2003) designed an experiment to test a hypothesis that the dialogic-reading intervention could produce greater gains in language and literacy skills of children compared with those engaged in typical parent-child reading. Eighty-six Hong Kong Chinese kindergarten children were tested on a Chinese literacy test and a picture vocabulary test before and after the program. Results of the study indicated that the children in the dialogic reading group benefited significantly from the intervention. In addition, early literacy-related activities at home had strong and direct effects on both children's literacy growth and language development in Chinese. Through a series of the studies, DR has been found to have a positive influence on children's language skills, especially vocabulary.

Even though research on reading intervention in kindergarten children is growing, few researchers have examined Thai parent-child reading specifically in English language. This study attempted to generate information and inspired further pertinent research to the field. With respect to Whitehurst's work, this study focused on the dialogic reading method. This research investigated further on the factors associated with children's vocabulary development: parents' backgrounds, frequency of parent-child reading, and beliefs about L2 learning. In response to the literature, the researcher investigated the following questions:

1) What are the characteristics of parents and their children who engage in the parent-child reading program?

2) What are the levels of parents' perceptions of English competence?

3) What are the reasons for reading with children as reported by their parents?

4) What beliefs about English language learning do Thai parents report?

5) Regarding the PEER sequence, what are the strategies that the parents use during bookreading?

6) Is there any significant difference between the children's scores on English vocabulary before and after participating in the reading program?

7) What combination of variables (i.e., household income, education, frequency of reading, English competence, beliefs, dialogic reading strategies, and child age) best predicts children's vocabulary achievement?

\section{Method}

The data for this study were from a parent-child reading program, an experimental design study conducted as part of research funded by School of Liberal Arts, University of Phayao, Thailand. Kindergarten children and their parents were recruited to participate in the study. Demographic information was collected at a training session. The children's lexical development was assessed before and after participating in the program.

\subsection{Participants}

The participants were 54 single parents and their 54 children (aged 3 to 6 years old). Among the children, 52\% were boys, $48 \%$ were girls. On average, the children were four years old. The children attended kindergarten 1-3 (3 different classes) at a school in Phayao province, Thailand. The school is private and served 3-6 year-old children. Three kindergarten teachers and the parents were informed of the parent-child reading program. They participated voluntarily in this study. The study was conducted collaboratively with three main parties: the researcher, the teachers, and the parents.

\subsection{Materials}

Since all participants speak Thai as their primary language, the materials were explained in Thai except the self-evaluation of English competence that was explained in English. The research materials were as follows: 


\subsubsection{Questionnaires}

The goal was to investigate parent-child characteristics (e.g. household income, English language competence, and child age), the frequency of shared reading, and the use of PEER sequence strategies. In response to the goal, two questionnaires (pre-and post- reading program) were used to collect the data.

The pre-program questionnaire was distributed to the parents during the training session. The questionnaire consisted of five main parts: 1) demographic data and a self-evaluation of English competence; 2) children's information; 3) reasons for reading; 4) beliefs about English language learning; and 5) comment(s). Some question items on demographic information and reasons for reading were adapted from a public report on the frequency of parent-child reading in Thailand (National Statistical Office, 2011) and some items were developed for the present study. Regarding a self-evaluation of English competence (Clémont \& Baker, 2001), the researcher asked the parents to use four 6-point scales to indicate how well they could use English in reading, writing, speaking, and comprehension. The questions on the frequency of reading were adapted from research conducted by Monica Westerlund and Dagma Lagerberg (2008). After being granted permission from Westerlund and Lagerberg to use the question items in this study, the researcher translated them from English into Thai so that the parents were able to answer the questions effectively. Only the parents who involved in the study could fill out the questionnaire. The last part was to explore the parents' beliefs about English language learning. To investigate the parents' beliefs, the researcher was granted permission from Professor Elaine Horwitz to use BALLI in this study. Regarding BALLI, the original questionnaire consisted of 44 items. Two items were eliminated because the questions were not relevant to the purposes of the study. With respect to Horwitz's (2012) work, the BALLI measures beliefs about five themes: 1) foreign language aptitude, 2) the difficulty of language learning, 3) the nature of language learning, 4) learning and communication strategies, and 5) motivations and expectations. All 40 items were rated on a 5-point rating scale ranging from strongly agree (5), to strongly disagree (1). For item 4, the question was about the difficulty of the English language, the scales ranging from very difficult (1) to very easy (5). The item 15 , the respondents were asked to indicate how long it took to learn English very well.

The post-program questionnaire consisted of three main parts: 1) the reading behaviors; 2) the dialogic reading (DR) activities; and 3) comment(s). The question items about the dialogic reading strategies or the PEER sequence and sub-activities included: 1) encouraging your child to talk about the story; 2) evaluating your child's interaction; 3) giving more information to stimulate your child's imagination and conversation; 4) repeating after reading; 5) paying attention to your child's need and interest; 6 ) communicating with your child and draw his/her interest; 7) giving your child praise or feedback; and 8) sharing experience during reading. The respondents were allowed to select more than one activity that they contributed during reading. The parents were also asked to write a comment and to give answers to the open-ended questions: "Are you going to continue reading a book with your child?" "If not, would you please give us a reason?"

\subsubsection{A Picture Aesop Book and Audio CD-Rom}

The book consisted of four Aesop fable stories: 1) The Hen and the Golden Eggs, 2) A Father and His Sons, 3) The Businessman and Donkey, and 4) The Father, his Son, and their Ass. The CD-Roms of the audio fable narrations were also provided to ensure that every child and his/her parent would listen to the stories, pronounce words appropriately, and read along.

\subsubsection{Receptive Vocabulary Test}

The lexical knowledge was measured within the context of parent-child reading using the DR method. The researcher assessed the children's English vocabulary knowledge with a fourteen picture vocabulary test developed by the researcher in accordance with the picture vocabulary found in an Aesop book given to the parents. Overall reliability of the vocabulary test (alpha) was .78, which is acceptable for a teacher made test (Wells \& Wollack, 2003). The test words were well clarified in the storybook with illustrations. The test was designed to measure English receptive (hearing) vocabulary of the children in this study. Each test item consisted of four different pictures, representing four different words. At each page, there were four blocks, black and white drawings.

\subsection{Procedures}

The reading program was conducted for six weeks, between Mid-June and July 2013. During the first week, the researcher trained the parents on how the dialogic reading worked, and what they could do to promote their children's reading. Since this study focused on how parents' DR implementing at home affected children's language and literacy acquisition, the training session focused on the parents rather than on the children. In the 
training session, parents were trained to use DR and to use the materials for DR through live instruction and demonstration conducted by the researcher. Then, an initial survey was given to the parents whereas all children were individually pretested on fourteen target English words. In so doing, the researcher or the test administrator read a word and asked a child to point to a picture that represented that specific word. The test administrator had to make sure that the children understood the direction before the test began. It took approximately 5-10 minutes per a child to complete the test.

The parents read with their children for four weeks. Each parent was provided with a book of four different Aesop fables and a guideline about the PEER sequence. In response to the purposes of the study, parents were expected to read with their children using the PEER sequence. Each week, the parents were assigned to read an Aesop fable to their children. This way, one story covered 7 days with 30-40 minutes per day. Supervision was also provided to the teachers and the parents during the 4-week program. Each class was visited twice a week in person or over the phone to ensure that teachers mentored, facilitated the parents and the children; and to find out whether they encountered any problems. The teachers acted as the facilitators in the data collection and concurrently encouraged the parents to continue reading with their children. The teachers worked collaboratively and closely with the parents such as weekly monitoring the reading program. Some families sent some pictures of parent-child reading activities to the researcher and the teachers electronically.

The sixth week, children were then immediately posttested on the vocabulary by way of the same measurement used in pretesting. The post-program questionnaire was distributed to the parents. Also contributing importantly to the use of DR, the parents were asked to report specific strategies (the PEER sequence) that they used while reading at home.

\section{Results}

Descriptive statistics (mean, standard deviation, and frequency) for variables in this study are shown in Tables 1, 2, and 3. Based on Horwitz's (1988) five main themes, the results of parents' beliefs about English language learning are described in details. Multiple regression analysis was used to determine relationships among the variables. It was found that some variables are related to each other at various levels of relation.To explore reciprocity of the 54 children's lexical achievement before and after engaging in the reading program, the pretest and posttest scores are statistically reported.

\subsection{Parent-Child Characteristics and Achievement}

Parents were administered a background questionnaire including parents' income, education levels, and frequency of reading with their children to develop a measure based on a combination of these factors (e.g., Zhang, Tardif, Shu, Li, Liu, McBride-Chang, Liang, \& Zhang, 2013). Household income was measured with a 10 -point scale, with $1=$ less than $10000,2=$ between 10001 and $15000,3=$ between 15001 and $20000,4=$ between 20001 and $25000,5=$ between 25001 and $30000,6=$ between 30001 and $35000,7=$ between 35 001 and $40000,8=$ between 40001 and $45000,9=$ between 45001 and 50000 , and $10=$ more than 50000 Thai baht (THB) per month. Parent education was measured with a 3-point scale such that $1=$ below bachelor degree, 2 = bachelor degree, and $3=$ graduate degrees. Frequency of reading with children per week was measured with a 4-point scale, with $1=$ never, $2=1-2,3=3-4$, and $4=$ more than 4 times. Parents' self evaluation of English competence was measured with a 6-point scale ( 1 = quite badly, $6=$ very well). The beliefs about language learning (BALLI) was measured with a 5 -point scale $(1=$ strongly disagree, $5=$ strongly agree). For children's ages were measured with a 6-point scale, with $1=$ less than $3,2=3,3=4,4=5,5=6$, and $6=$ more than 6 years old.

For this study, three indicators were used to characterize parents' backgrounds: household income, parent education, and the frequency of reading with a child. In the present sample, average educations and incomes are presented in Table 1. On average, the family income for this measure ranged between 15000 and 25000 THB per month (approximately US $\$ 1$ = THB 32.08 using 2013 Thaifxrates.net) which was higher than the minimum wage in Thailand (Ministry of Labour, 2013). To get the most accurate information of the parents' education, the researcher used the highest education that was reported by the 54 parents in the present study. The mean for parent education was baccalaureate. As Table 1 indicates, the parents read with their children more frequently during the reading program than they did before engaging in the program. On average, the parents read with their children three to four times per week. A measure of the parents' English competence was assessed using the self-evaluation (Clémont \& Baker, 2001). On average, the parents perceived that their English skills (reading, writing, speaking, and comprehension) were at the level of "all right" across all skills. Parents' beliefs about English learning were neutral or agree across the five themes (Horwitz, 1988). Average age of the 54 children was four years old. As shown in Table 1, the children had the average posttest scores of $8.26(S D=3.06)$, and 
the average pretest scores of $3.70(S D=1.48)$ out of 14 . Finally, the number of PEER sequence strategies that the parents used during reading with their children was coded and assessed. The mean for this analysis was 3.33 $(S D=1.42)$, indicating that, on average, the parents employed three strategies.

Table 1. Means and standard deviations for all variables

\begin{tabular}{|c|c|c|c|}
\hline Variable & $M$ & $S D$ & Range \\
\hline \multicolumn{4}{|l|}{ Parent characteristics } \\
\hline Household income & 3.78 & 2.47 & $1-10$ \\
\hline Parent education & 1.80 & .68 & $1-3$ \\
\hline Frequency of reading (before the program) & 2.38 & 1.18 & $1-4$ \\
\hline Frequency of reading (during the program) & 2.98 & .81 & $1-4$ \\
\hline \multicolumn{4}{|l|}{ Parent self-evaluation of English competence } \\
\hline Reading & 3.15 & 1.15 & $1-6$ \\
\hline Writing & 3.11 & 1.22 & $1-6$ \\
\hline Speaking & 3.09 & 1.27 & $1-6$ \\
\hline Comprehension & 3.06 & 1.22 & $1-6$ \\
\hline \multicolumn{4}{|l|}{ BALLI } \\
\hline Foreign language aptitude & 3.71 & 1.03 & $1-5$ \\
\hline Difficulty of language learning & 3.15 & 1.29 & $1-5$ \\
\hline Nature of language learning & 3.63 & 1.19 & $1-5$ \\
\hline Learning and communication strategies & 3.53 & 1.25 & $1-5$ \\
\hline Motivations and expectations & 3.64 & 1.10 & $1-5$ \\
\hline \multicolumn{4}{|l|}{ Child characteristics and achievement } \\
\hline Age & 3.24 & .98 & $1-6$ \\
\hline Pretest & 3.70 & 1.48 & $0-14$ \\
\hline Posttest & 8.26 & 3.06 & $0-14$ \\
\hline Dialogic reading strategies & 3.33 & 1.42 & $1-8$ \\
\hline
\end{tabular}

$N=54$ participants

\subsection{Reasons for Reading}

The 54 single parents were asked to indicate one or more reasons for reading to their children. The results collected before and after the parent-child reading program were the same. Most frequently selected reasons were "improving a child's knowledge", "warmth of family", "developing a child's listening", and "developing a child's emotion" respectively. Few parents selected "being a good sample to a child", "learning new words", and “developing a child's imagination" as reasons for reading to their children (see Table 2). 
Table 2. Reasons for reading

\begin{tabular}{ll}
\hline Reasons & Frequency $(n)$ \\
\hline Knowledge & 40 \\
Emotional development & 21 \\
Warmth of family & 25 \\
Good sample to children & 13 \\
Learn of new words & 14 \\
Listening development & 24 \\
Development of imagination & 14 \\
Others & 10 \\
\hline
\end{tabular}

\subsection{Beliefs about English Language Learning}

According to Horwitz's (1988) five themes, the data from BALLI were analyzed and interpreted as follows:

\subsubsection{Foreign Language Aptitude}

It was found that the participants agreed with the statements of most items. Half of the participants $(50 \%, n=27)$ strongly believed that it was easier for children than adults to learn a foreign language. Over $70 \%$ of the respondents believed that some people had a special ability for learning foreign languages, and that Thai people could learn to speak a foreign language $(65 \%, n=35)$. A majority $(67 \%, n=36)$ strongly disagreed or disagreed with the statement that people who were good at mathematics or science were not good at learning foreign languages.

\subsubsection{Difficulty of Language Learning}

A large proportion $(73 \%, n=39)$ strongly agreed or agreed with the statement that some languages were easier to learn than others, and nearly half $(47 \%, n=25)$ reported that English language was at a medium level of difficulty. Only a few participants $(10 \%, n=5)$ agreed with the statement that spending less than one hour per week learning a foreign language would take them less than one year to speak the language very well.

\subsubsection{The Nature of Language Learning}

One-third of the participants indicated that it was best to learn English in an English-speaking country. Many strongly believed that the most important part of learning English was learning vocabulary $(58 \%, n=31)$.

\subsubsection{Learning and Communication Strategies}

Responses to the items on learning and communication strategies indicated a large proportion $(50 \%, n=27)$ of the respondents strongly disagreed or disagreed with the statement that everyone could learn to speak a foreign language reflecting that the ability to learn a foreign language depended on individual capability. Many strongly believed that it would be difficult for beginning students to speak correctly if they were allowed to make mistakes $(58 \%, n=31)$. A small percentage $(8 \%, n=4)$ of the respondents strongly disagreed with the statement that it was important to speak English with an excellent pronunciation. Over $70 \%$ of the participants strongly disagreed or disagreed with the statement that one should not say anything in English until one could say it correctly. Further, they enjoyed practicing their English with English native speakers (58\%, $n=31 \%)$, and with multi-media such as cassettes or CD Roms $(76 \%, n=41)$. Approximately $28 \%(n=15)$ of the participants reported that they felt timid speaking English with other people.

\subsubsection{Motivations and Expectations}

Fifty-seven percent ( $n=31$ ) of the participants wanted to speak English very well. Over $60 \%$ of the participants would like to learn English so that they could get to know English native speakers. Approximately half of the participants would like to have English-speaking friends. An overwhelming majority $(82 \%, n=44)$ of the respondents believed that if they learned to speak English very well, they would have better opportunities for a good job.

\subsection{Dialogic Reading Strategies}

The parents were allowed to indicate one or more strategies as clarified in the following activities in Table 3 . The findings indicated that the parents tended to give their children more information to stimulate the children's 
imagination and communication. The parents also indicated that they repeated what they read to their children. Few parents selected "paying attention to their children's need and interest", "sharing experience with their children", or "giving their children praise or feedback."

Table 3. Parent-child reading activities

\begin{tabular}{lc}
\hline Reading activities & $(n)$ \\
\hline Encouraging your child to talk about the story & 32 \\
Evaluating your child's interaction & 23 \\
$\begin{array}{l}\text { Giving more information to stimulate your child's imagination and } \\
\text { conversation }\end{array}$ & 41 \\
Repeating after reading & 33 \\
Paying attention to your child's need and interest & 6 \\
Communicating with child and draw his/her interest & 22 \\
Giving your child praise or feedback & 12 \\
Sharing experience during reading & 11 \\
\hline
\end{tabular}

\subsection{Vocabulary Measures}

There was a significant increase in the posttest across all words, and some words were dramatically increased such as donkey, old, and sons. To address the sixth research question, the pretest and posttest scores were statistically calculated (see Table 1). It was found that the 54 children had the average posttest scores of 8.26 (SD $=3.06)$ which was significantly higher than the average pretest scores of $3.70(S D=1.48), t(53)=-9.52, p=.00$ at the alpha level of .05. The pretest and posttest scores were computed to indicate the gain scores (see Appendix A). After comparing the scores between the tests, eighteen children who gained more than five scores different were investigated further to examine whether the factors (household income, parent background and frequency of reading) influenced the children' lexical development. The results of further analyses showed that approximately half of these eighteen children's parents had household income payment between less than 10000 baht and 20000 baht per month, and 60\% $(n=11)$ of these parents graduated with bachelor or higher degrees.

\subsection{Multiple-Variable Correlations}

Table 4 describes the correlations among all measurements, including parents and children's characteristics, parents' perception of English competence, beliefs about language learning, and children's achievement. Significant correlations were found in some variables. Specifically, parent education was significantly related to the frequency of reading $(r=-.27, p<.05)$. Subsequent analysis (not presented here) showed that there was a relationship between the frequency of reading before and after the program $(r=.32, p<.05)$. To examine the parents' English language skills, reading was found strongly related to comprehension $(r=.81, p<.01)$, speaking $(r=.80, p<.01)$, and writing $(r=.73, p<.01)$ respectively. In addition, English comprehension was found strongly related to writing $(r=.83, p<.01)$ and speaking $(r=.86, p<.01)$, whereas speaking was significantly related to writing $(r=.81, p<.01)$. Finally, the results regarding the parents' beliefs about English learning indicated that the parents' beliefs on difficulty of language learning were related to the nature of language learning $(r=.33, p<.01)$, and motivations and expectations $(r=.51, p<.01)$. In addition, the nature of language learning was moderately related to the learning and communication strategies $(r=.40, p<.01)$, and motivations and expectations $(r=.38, p<.01)$. To address the seventh research question, multiple regression analysis was used to test if all variables significantly predicted the children' achievement. It was found that one predictor produced $R^{2}=.143, F(3,50)=2.770, p<.05$. According to the result, the number of the PEER sequence strategies that the parents used in the reading program had significantly positive regression weights, indicating that children whose parents used a larger number of the PEER sequence strategies were expected to have higher vocabulary scores. 
Table 4. Correlations among sample characteristics, parents' beliefs and vocabulary achievement

\begin{tabular}{|c|c|c|c|c|c|c|c|c|c|c|c|c|c|c|c|c|}
\hline Variable & 1 & 2 & 3 & 4 & 5 & 6 & 7 & 8 & 9 & 10 & 11 & 12 & 13 & 14 & 15 & 16 \\
\hline 1. Pretest & - & & & & & & & & & & & & & & & \\
\hline 2. Posttest & -.086 & - & & & & & & & & & & & & & & \\
\hline 3. Household income & -.090 & .120 & - & & & & & & & & & & & & & \\
\hline 4. Parent's education & -.042 & -.182 & .196 & - & & & & & & & & & & & & \\
\hline 5. Child's age & -.002 & .141 & .084 & -.177 & - & & & & & & & & & & & \\
\hline 6. Frequency of reading & .058 & .169 & -.002 & $-.279 *$ & -.018 & - & & & & & & & & & & \\
\hline 7. Reading & -.062 & .042 & -.074 & .063 & -.015 & -.037 & - & & & & & & & & & \\
\hline 8. Comprehension & .009 & -.004 & -.096 & -.031 & -.011 & -.018 & $.810^{* *}$ & - & & & & & & & & \\
\hline 9. Writing & -.137 & .048 & -.048 & .028 & .024 & .021 & $.735 * *$ & $.830 * *$ & - & & & & & & & \\
\hline 10. Speaking & -.045 & .076 & -.011 & .000 & -.003 & -.089 & $.808^{* *}$ & $.868 * *$ & $.814^{* *}$ & - & & & & & & \\
\hline 11. FLA & .016 & -.140 & .009 & -.038 & -.221 & .041 & -.018 & -.001 & -.122 & .023 & - & & & & & \\
\hline 12. DLL & -.113 & .063 & -.149 & .146 & -.091 & -.070 & .070 & .004 & .041 & -.021 & -.098 & - & & & & \\
\hline 13. NLL & -.002 & .119 & .100 & .262 & .060 & .108 & -.070 & -.080 & .009 & -.068 & -.133 & $.332 * *$ & - & & & \\
\hline 14. LCS & .006 & .007 & -.061 & .102 & .018 & .091 & -.224 & -.166 & -.202 & -.228 & -.009 & .002 & $.406^{* *}$ & - & & \\
\hline 15. ME & -.047 & .026 & -.052 & .073 & -.245 & .131 & .022 & .096 & .078 & .014 & .062 & $.510^{* *}$ & $.384 * *$ & -.007 & - & \\
\hline 16. DR & - & $.334 *$ & .221 & -.014 & .290 & -.163 & -.188 & -.248 & -.163 & -.193 & .083 & .038 & .235 & .095 & .127 & - \\
\hline
\end{tabular}

Note. Frequency of reading $=$ the frequency of reading during the reading program; FLA $=$ Foreign language aptitude; DLL = Difficulty of language learning; NLL = Nature of language learning; LCS $=$ Learning and communication strategies; $\mathrm{ME}=$ Motivations and expectations; $\mathrm{DR}=$ Dialogic reading strategies

${ }^{*} p<.05,{ }^{* *} p<.01$; Dashes represent empty cells or no information because the variables are not tested in the study.

\section{Discussion}

The purposes of this study were to explore parents' backgrounds, beliefs about English language learning, and to compare the English vocabulary development of three to six year-old-children before and after engaging in the parent-child reading program with the dialogic reading method. It was expected that the interaction between the parents and their children through conversation would assist the children's lexical development, since the dialogic reading provided opportunities for them to talk about the stories and book-related vocabulary, and to share experience in particular. By so doing, it was hypothesized that this program would have an extensive effect on children's vocabulary development.

Findings of this study showed that the children learned new words at a prodigious rate and performed better on the picture vocabulary test after participating in the reading program. It could indicate that parental involvement in young children's reading helped improve their vocabulary knowledge. Consistent with the results indicating that the parents read with their children, on average, three or four times per week and used PEER sequence strategies to promote the children's lexical learning. Reading for knowledge and warmth of family were seen as casual factors that might encourage the parents to continue reading with their children. Regarding the open-ended questions in the post-program questionnaire, all parents also stated that they would continue reading with their children.

In addition, analyses yielded relationships among the variables. The number of uses of the PEER sequence strategies had a moderate relationship with the children's achievement. The results from the descriptive analyses were used to explain this finding. Parents reported that they gave more information to stimulate their children's imagination and conversation, encouraged the children to talk about the story, and repeated what they read before finishing their reading. The DR method itself encourages children to play the roles as storytellers and masters in reading (Brannon \& Dauksas, 2013). Consequently, the PEER sequence was assumed to increase these young children's vocabulary. In addition, it was found that parents' educational attainment was related to the frequency of reading. For this sample, parents who graduated with a bachelor degree read with their children more frequently than those who did not go to college. Scarborough and Dobrich (1994) also found that parents' education was associated with the relatively high frequency of shared-bookreading at home. A result of a study 
by Administration for Children and Families (2006) showed that children whose parents read to them at least three times a week had greater vocabulary scores than children whose parents read to them less frequently. Consequently, a higher frequency of parent-child reading might affect children's greater gains on vocabulary.

The findings of the descriptive analyses showed that, on average, parents rated their English competence at the level of "all right" across all skills. Regarding the correlations, the parents' English competence showed multiple relationships among four English language skills including reading, writing, speaking, and comprehension. Reading had strong positive relationships with comprehension, speaking, and writing. Comprehension had strong positive relations with speaking and writing. Speaking was strongly associated with writing. Even though these variables were strongly related, they had no relationship with the children's achievement; however, they indicated the reliability of the parents' self-evaluation of English ability.

Beliefs about English learning indicated that parents' motivation and expectations in learning the English language were moderately related to their beliefs about the nature and difficulty of language learning and communication strategies. Even though these findings were not associated with the children's vocabulary achievement, parents' beliefs might affect the children's literacy indirectly. To elucidate this statement, the parents reported that they considered achieving career goals and better job opportunities as their primary motivation to improve their English. Thus, they expected their children to do well in English language learning, as evidenced by the results of the descriptive analyses. These results are consistent with the findings of the studies indicating that Chinese and Brazilian participants showed the desire to learn English as it was prompted by the desire to get a better job or promotion as a means of social ascension (Yong \& Campbell, 1995; Friedrich, 2000). The parents in the present study reported that learning English was difficult, so vocabulary was crucial in order to learn the language. Therefore, they expected their children to learn new English words every day. Likewise, Vibulphol (2004) found that Thai participants realized that vocabulary was important in learning English.

\section{Implications}

In spite of the fact that it is not possible to generalize these findings to all Thai families, this study has several implications for parents, teachers, and policy makers who work with EFL children and families. First, this study supports the home reading program using the dialogic reading method which has a positive impact on children's achievement and family literacy (Stirling McDowell Foundation, 2001; Zevenbergen \& Whitehurst, 2003). Previous studies have demonstrated that reading with parents established a great deal of valuable communication and improvement of vocabulary. Consequently, it is recommended that parents should spend more quality time with their children. Deciding how to help their children improve both academic knowledge and quality of life should be priorities. In addition, it is recommended that parents pay attention to their children's personalities, abilities, needs, and interests. Second, teachers should encourage the parents and their children to participate in a reading program. According to the results of the current study, teachers were willing to assist the participants and encourage them to continue reading. Teachers had opportunities to observe measurable gains before and after the study. For their own practice, teachers may follow up on their students' achievement from time to time as well as working collaboratively with the parents. It is also recommended that teachers or schools include parental involvement in child reading programs as part of their course work. Finally, along with other implications, national and local policy makers who involve in essentially political concerns should consider parent-child reading programs as a crucial path to national success. As evidenced by the earlier statistical report on Thai parent-child reading nationwide, it is important to promote young children literacy. In order to give appropriate assistance to children, policy makers should strive to collaborate with school districts, teachers, parents, and communities, so that they will recognize the variety of children's abilities, personalities, needs, strengths, and weaknesses. In so doing, policy makers may realize that one policy may not serve everyone in the country.

\section{Limitations and Directions for Future Research}

This study has several limitations. First, the sample size of the study was relatively small, so the researcher could not contribute to variations of participants' backgrounds or levels of English proficiency. Second, parents were comfortable with follow-up interviews at school when they picked up their children, so the home observations were not conducted. However, many of them sent some photos of their reading activities to the researcher and the teachers electronically. Another limitation is that the researcher analyzed receptive vocabulary that is generally associated with several linguistic elements, without dividing it into specific categories. There are many possible subdivisions that could be made on the basis of lexical analysis, such as single-word stimuli, phonological or semantic processing. All these divisions appear to equally affect the degree of English lexical development in children. Future research should undertake an in-depth examination of the information that is 
associated with second language acquisition and the participants' experiences during the reading program. In addition, future research should consider the varieties of vocabulary assessment, and the implementation of dialogic reading with participants from various backgrounds.

\section{Conclusion}

This study investigated the influence of parent-child backgrounds (household income, parent education, and frequency of reading, and child's age,), beliefs about English learning, and a dialogic reading method on Thai kindergarteners' English lexical development. Since research focusing on parent-child reading and the implementation of the dialogic reading method among Thai children had not been conducted, this study gives support to pertinent research to these areas that are becoming increasingly essential. The findings of the current study showed that parents across all backgrounds were actively involved in their children's reading that was congruent with their positive attitudes toward FL learning. It was also found that frequent reading and the dialogic reading method significantly promoted children's early lexical development.

\section{Acknowledgements}

The author would like to acknowledge the support provided by various individuals. Sincere thanks are given to Mr. Christopher Beard and Miss Nattira Kamkhad for their kindly help and support for this study, and to the kindergarten teachers and students along with their parents for their participation. Finally, I would like to thank my husband, Mr. Sanit Petchprasert, for sketching all the pictures.

\section{References}

Administration for Children and Families. (2006). Head Start Performance Measures Center, Family and Child Experiences Survey (FACES 2000): New research on Head Start outcomes and program quality. Washington, DC: Author.

Brannon, D., \& Dauksas, L. (2013). Making parents partners to increase young children's expressive language skills. Journal of Missouri Reading Association, 37(1), 34-41.

Bus, A. G., van Ijzendoorn, M. H., \& Pellegrini, A. D. (1995). Joint book reading makes for success in learning to read: A meta-analysis on intergenerational transmission of literacy. Review of Educational Research, 65, $1-21$.

Chappuis, S., \& Stiggins, R. J. (2002). Classroom assessment for learning. Educational Leadership, 60(1), 40-43.

Chow, B. W. Y., \& McBride-Chang, C. (2003). Promoting language and literacy development through parent-child reading in Hong Kong preschoolers. Early Education \& Development, 14(2), 233-248.

Chow, B. W. Y., McBride-Chang, C., Cheung, H., \& Chow, C. S. L. (2008). Dialogic reading and morphology training in Chinese children: Effects on language and literacy. Developmental Psychology, 44, 233-244.

Clémont, R., \& Baker, S. C. (2001). Measuring social aspects of L2 acquisition and use: Scale characteristics and administration.

Davis-Kean, P. E. (2005). The influence of parent education and family income on child achievement: The indirect role of parental expectations and the home environment. Journal of Family Psychology, 19, 294-304.

Friedrich, P. (2000). English in Brazil: Functions and attitudes. World Englishes, 19(2), 215-223.

Gardner, R. C. (1985). Social psychology and second language learning: The role of attitudes and motivation. London: Edward Arnold.

Hart, B., \& Risley, T. R. (1995). Meaningful differences in the everyday experience of young American children. Baltimore: Brookes.

Horwitz, E. K. (1988). The beliefs about language learning of beginning university foreign language students. The Modern Language Journal, 72, 283-294. http://dx.doi.org/10.1111/j.1540-4781.1988.tb04190.x

Horwitz, E. K. (2012). Becoming a language teacher: A practical guide to second language learning and teaching (2nd ed.). Boston: Pearson Education.

Lee, J., \& Bowen, N. K. (2006). Parent involvement, cultural capital, and the achievement gap among elementary school children. American Educational Research Journal, 43, 193-215.

Ministry of Labour. (2013). Minimum wage. Retrieved December 24, 2013, from http://www.mol.go.th/en/employee/interesting_information/6319. 
National Statistical Office. (2011). A report of the national adults reading to their children. Bangkok: National Statistical Office, Ministry of Information and Communication Technology.

Neuman, S. B. (1999). Books make a difference: A study of access to literacy. Reading Research Quarterly, 34, 286-311.

Opel, A., Ameer S., \& Aboud, F. E. (2009). The effect of preschool dialogic reading on vocabulary among rural Bangladeshi children. International Journal of Educational Research, 48, 12-20.

Raikes, H., Alexander, P. B., Luze, G., Tamis-LeMonda, C. S., Brooks-Gunn, J., Constantine, J., ... Rodriguez, E. T. (2006). Mother-child bookreading in low-income families: correlates and outcomes during the first three years of life. Child Development, 77, 924-953. http://dx.doi.org/10.1111/j.1467-8624.2006.00911.x

Saito, Y. (2003). The use of self-assessment in second language assessment. Retrieved December 19, 2013, from http://www.tc.columbia.edu/academic/tesol/WJFiles/pdf/Saito_Forum.pdf

Scarborough, H. S., \& Dobrich, W. (1994). On the efficacy of reading to preschoolers. Developmental Review, 14, 245-302.

Short, D. J. (1993). Assessing integrated language and content instruction. TESOL Quarterly, 27, 627-656.

Sim, S. H. (2012). Supporting children's language and literacy skills: The effectiveness of shared book reading intervention strategies with parents ( $\mathrm{PhD}$ thesis, Queensland University of Technology).

Snow, C. E., Burns, M. S., \& Griffin, P. (1998). Preventing reading difficulties in young children. Washington, DC: National Academy Press.

Stirling McDowell Foundation, (2001). Research report: Home reading program for grade one children. Retrieved August 14, 2013, from http://www.mcdowellfoundation.ca/main_mcdowell/projects/research_rep/62_home_read ing_program.pdf

Storch, S. A., \& Whitehurst, G. J. (2001). The role of family and home in the literacy development of children from low-income backgrounds. New Directions for Child and Adolescent Developmen, 2001(92), 53-72. http://dx.doi.org/10.1002/cd.15.

Sung, H., \& Padilla, A. M. (1998). Student motivation, parental attitudes, and involvement in the learning of Asian languages in elementary and secondary schools. Modern Language Journal, 82(2), 205-216.

Vibulphol, J. (2004). Beliefs about language learning and teaching approaches of pre-service EFL teachers in Thailand (Unpublished Ph.D thesis, Oklahoma State University, United States Oklahoma).

Wang, S. (1996). A study of Chinese English majors' beliefs about language learning and their learning strategies. Dissertation Abstracts International, 57(12), 5021A. (UMI No. 9716564).

Wells, C. S., \& Wallack, J. A. (2003). An Instructor's Guide to Understanding Test Reliability. Retrieved August 25, 2013, from http://testing.wisc.edu/Reliability.pdf

Westerlund, M., \& Lagerberg, D. (2008). Expressive vocabulary in 18-month-old children in relation to demographic factors, mother and child characteristics, communication style and shared reading. Child: Care, Health and Development, 34.

Whitehurst, G. J., Epstein, J. N., Angell, A. L., Payne, A. C., Crone, D. A., \& Fishcel, J. (1994). Outcomes of an emergent literacy intervention in Head Start. Journal of Educational Psychology, 86, 542-555.

Whitehurst, G. J., Falco, F. L., Lonigan, C. J., Fischel, J. E., DeBaryshe, B. D., Valdez-Menchaca, M. C., \& Caulfield, M. (1988). Accelerating language development through picture bookreading. Developmental Psychology, 24, 552-559.

Whitehurst, G. J. (n.d.). Dialogic reading: An effective way to read to preschoolers. Retrieved August 25, 2013, from http://www.readingrockets.org/article/400/

Yong, Z., \& Campbell, K. P. (1995). English in China. World Englishes, 14(3), 377-390.

Zhang, Y., Tardif, T., Shu, H., Li, H., Liu, H., McBride-Chang, C., ... Zhang, Z. (2013). Phonological skills and vocabulary knowledge mediate socioeconomic status effects in predicting outcomes for Chinese children. Developmental Psychology, 49(4), 665-671.

Zevenbergen, A. A., \& Whitehurst, G. J. (2003). Dialogic reading a shared picture book intervention for preschoolers. In A. Kleeck, S. Stahl, \& E. Bauer (Eds.), On Reading Books to Children: Parents and Teachers. Mahwah, NJ: Erlbaum. 


\section{Appendix}

Data for the comparison of children's pretest posttest gains

\begin{tabular}{llllllll}
\hline Subject & Pretest & Posttest & Gain & Subject & Pretest & Posttest & Gain \\
\hline 1 & 3.00 & 4.00 & 1 & 28 & 1.00 & 9.00 & 8 \\
2 & 3.00 & 4.00 & 1 & 29 & 3.00 & 6.00 & 3 \\
3 & 2.00 & 5.00 & 3 & 30 & 4.00 & 8.00 & 4 \\
4 & 3.00 & 3.00 & 0 & 31 & 2.00 & 5.00 & 3 \\
5 & 4.00 & 4.00 & 0 & 32 & 5.00 & 4.00 & -1 \\
6 & 5.00 & 6.00 & 1 & 33 & 4.00 & 7.00 & 3 \\
7 & 6.00 & 8.00 & 2 & 34 & 4.00 & 7.00 & 3 \\
8 & 3.00 & 8.00 & 5 & 35 & 3.00 & 6.00 & 3 \\
9 & 5.00 & 11.00 & 6 & 36 & 3.00 & 4.00 & 1 \\
10 & 5.00 & 6.00 & 1 & 37 & 3.00 & 5.00 & 2 \\
11 & 6.00 & 10.00 & 4 & 38 & 4.00 & 6.00 & 2 \\
12 & 5.00 & 8.00 & 3 & 39 & 6.00 & 7.00 & 1 \\
13 & 5.00 & 12.00 & 7 & 40 & 3.00 & 4.00 & 1 \\
14 & 5.00 & 9.00 & 4 & 41 & 5.00 & 5.00 & 0 \\
15 & 4.00 & 9.00 & 5 & 42 & 4.00 & 5.00 & 1 \\
16 & 5.00 & 9.00 & 5 & 43 & 5.00 & 13.00 & 8 \\
17 & 5.00 & 6.00 & 1 & 44 & 5.00 & 9.00 & 4 \\
18 & 5.00 & 9.00 & 4 & 45 & 5.00 & 7.00 & 2 \\
19 & 5.00 & 10.00 & 5 & 46 & 1.00 & 9.00 & 8 \\
20 & 3.00 & 6.00 & 3 & 47 & 4.00 & 11.00 & 7 \\
21 & 4.00 & 10.00 & 6 & 48 & 1.00 & 10.00 & 9 \\
22 & 5.00 & 9.00 & 4 & 49 & 3.00 & 14.00 & 11 \\
23 & 4.00 & 9.00 & 5 & 50 & 1.00 & 13.00 & 12 \\
24 & 4.00 & 14.00 & 10 & 51 & 1.00 & 11.00 & 10 \\
25 & 6.00 & 12.00 & 6 & 52 & 1.00 & 13.00 & 12 \\
26 & 1.00 & 9.00 & 8 & 53 & 2.00 & 13.00 & 11 \\
27 & 4.00 & 11.00 & 7 & 54 & 2.00 & 14.00 & 12 \\
\hline & & & & & & &
\end{tabular}

\section{Copyrights}

Copyright for this article is retained by the author(s), with first publication rights granted to the journal.

This is an open-access article distributed under the terms and conditions of the Creative Commons Attribution license (http://creativecommons.org/licenses/by/3.0/). 